LAWRENCE LIVERMORE N A T IO N A L LABORATORY

\section{Update on NIF indirect drive ignition target fabrication specifications}

S. W. Haan, P. A. Amendt, T. R. Dittrich, S. P. Hatchett, M. C. Herrmann, O. A. Hurricane, M. M. Marinak, D. Munro, S. M. Pollaine, G. A. Strobel, L. J. Suter

October 17, 2003

Inertial Fusion Sciences \& Applications (IFSA) Monterey, CA, United States September 7, 2003 through September 12, 2003 
This document was prepared as an account of work sponsored by an agency of the United States Government. Neither the United States Government nor the University of California nor any of their employees, makes any warranty, express or implied, or assumes any legal liability or responsibility for the accuracy, completeness, or usefulness of any information, apparatus, product, or process disclosed, or represents that its use would not infringe privately owned rights. Reference herein to any specific commercial product, process, or service by trade name, trademark, manufacturer, or otherwise, does not necessarily constitute or imply its endorsement, recommendation, or favoring by the United States Government or the University of California. The views and opinions of authors expressed herein do not necessarily state or reflect those of the United States Government or the University of California, and shall not be used for advertising or product endorsement purposes. 


\title{
Update on NIF indirect drive ignition target fabrication specifications
}

\author{
S. W. Haan, P. A. Amendt, T. R. Dittrich, S. P. Hatchett, M. C. Herrmann, \\ O. A. Hurricane, M. M. Marinak, D. Munro, S. M. Pollaine, G. A. Strobel, ${ }^{1}$ and L. J. Suter \\ Lawrence Livermore National Laboratory, Livermore CA \\ ${ }^{1}$ also at Phys Department, Univ of Georgia, Athens GA
}

\begin{abstract}
Indirect drive ignition target simulations are described as they are used to determine target fabrication specifications. Simulations are being used to explore options for making the targets more robust, and to develop more detailed understanding of the performance of a few point designs. The current array of targets is described. A new target is described with radially dependent $\mathrm{Cu}$ dopant in Be. This target has significantly looser specifications for high-mode perturbations than previous targets. Current estimates of size limitations for fill tubes, holes, and isolated defect are discussed. Recent 3D simulations are described.
\end{abstract}

\section{INTRODUCTION}

This presentation is an update on the fabrication specifications as they result from the indirect drive ignition target design effort at LLNL. In general, recent work is in one of two areas. First, we are exploring options for making the target designs more robust. This includes better capsule optimization, graded $\mathrm{Cu}$ dopant in Be, and hohlraum design modifications. Second, we continue to pursue more detailed modeling of select point designs in order to enhance our confidence in their performance. This includes 3D modeling of the targets.

The basic design concept, and our understanding of the specifications, remains the same as it has been since NIF was proposed. The specifications are described in the previous proceedings. ${ }^{1,2}$ The target is a cylindrical hohlraum about $1 \mathrm{~cm}$ long by $6 \mathrm{~mm}$ diameter, of Au or a "cocktail" of $\mathrm{U}: \mathrm{Nb}_{0.14}: \mathrm{Au}: \mathrm{Ta}: \mathrm{Dy}$. The hohlraum is filled with $\mathrm{He}$ or $\mathrm{H}+\mathrm{He}$ gas contained by $1 \mu \mathrm{m} \mathrm{CH}$ or polyimide windows over each laser entrance hole (LEH). Each LEH is about $3 \mathrm{~mm}$ diameter. The LEH is coated with $30 \mu \mathrm{m}$ of $\mathrm{CH}$, which comes 600 microns up on the inside of the hohlraum. The capsule has a plastic or beryllium single shell ablator, about $120 \mu \mathrm{m}$ thick, supported by a $0.1 \mu \mathrm{m}$ thick polyimide tent. The ablator encloses a cryogenic solid DT layer about $80 \mu \mathrm{m}$ thick. The hohlraum may contain anti-convection foils, thickness less than $1 \mu \mathrm{m}$. While the basic design remains the same as it has been for a number of years, many details are being optimized as explained below.

\section{TARGET OPTIONS}

First regarding the hohlraum, there are various options that we should be maintaining. The hohlraum length could be between $7 \mathrm{~mm}$ (for sub-ignition implosions to verify target physics with half of NIF) up to $16 \mathrm{~mm}$ (large high-yield designs). Note that the LEH diameter is likely to stay at about 6-8 mm, independent of hohlraum size, because the laser spot size will probably be about the same for all the designs. The hohlraum material could be gold or the cocktail as mentioned above, and the fill could be pure $\mathrm{He}$ or a $\mathrm{H} / \mathrm{He}$ mixture. We are actively considering the specification on tenting. Anticonvection foils are possible, provided their mass is significantly less than the mass of the gas nominally included.

Designs using $0.5 \mu \mathrm{m}$ light $(2 \omega)$ may allow for considerably more energy delivered to the capsule, albeit possibly at lower drive temperature. From the point of view of capsule design and optimization, and target fabrication, the color of the light is not important; however, it does affect where one is likely to be in the parameter space of target size as the $2 \omega$ targets are considerably larger. Outer radii of Be targets could be as large as $2.5 \mathrm{~mm}$. Of course higher absorbed energy is very valuable to capsule performance; one example that has been examined in some detail is uniformly doped $\mathrm{Be}(\mathrm{Cu})$ capsules at $250 \mathrm{eV}$, for which the surface roughness specification increases from $10 \mathrm{~nm}$ (the so-called "NIF standard" surface roughness) at $250 \mathrm{~kJ}$ absorbed, to $60 \mathrm{~nm}$ at $600 \mathrm{~kJ}$ absorbed. The range of possibilities is only weakly dependent on the color of the laser light; either $2 \omega$ or $3 \omega$ could be used to drive large low temperature hohlraums, although $2 \omega$ would make it more likely that we would be fielding very big targets. 
Finally, the hohlraum designers are considering variants on the lining and fill of the hohlraum. Possibilities being considered include hohlraums filled with foam of $\mathrm{SiO}_{2}, \mathrm{GeO}_{2}$, or $\mathrm{XeO}_{2}$, all at about $1 \mathrm{mg} / \mathrm{cc}$; or linings on the hohlraum of about $1 \mu \mathrm{m}$ of $\mathrm{Kr}$ or Xe, while the hohlraum is filled with $0.1 \mathrm{mg} / \mathrm{cc}$ of He. Both of these variations work in simulations, and may improve laser-plasma interactions and/or cryogenic fielding.

We continue to consider the full suite of capsules described in ref. 1. An additional new design, Be with graded $\mathrm{Cu}$ dopant, is described in more detail below. We also continue to refine the capsule design. The hohlraum physics and laser performance will eventually set constraints on capsule size, pulse shape, and drive temperature. The main question we need to answer now, to guide target fabrication and the other elements of the program, is how to optimize the capsule performance given these constraints.

A new way to provide this optimization has been developed by one of us (Mark Herrmann). Herrmann's innovations are twofold: a better implementation of the constraints than previously, and an automated process that thoroughly optimizes over the remaining free parameters. From the point of view of target fabrication, this reoptimization has two consequences: the capsule dimensions are being adjusted, by perhaps $15-20 \%$ thickness increase on both ablator and fuel; and the specification on surface roughness may be loosened as the target design becomes more robust. (However, as

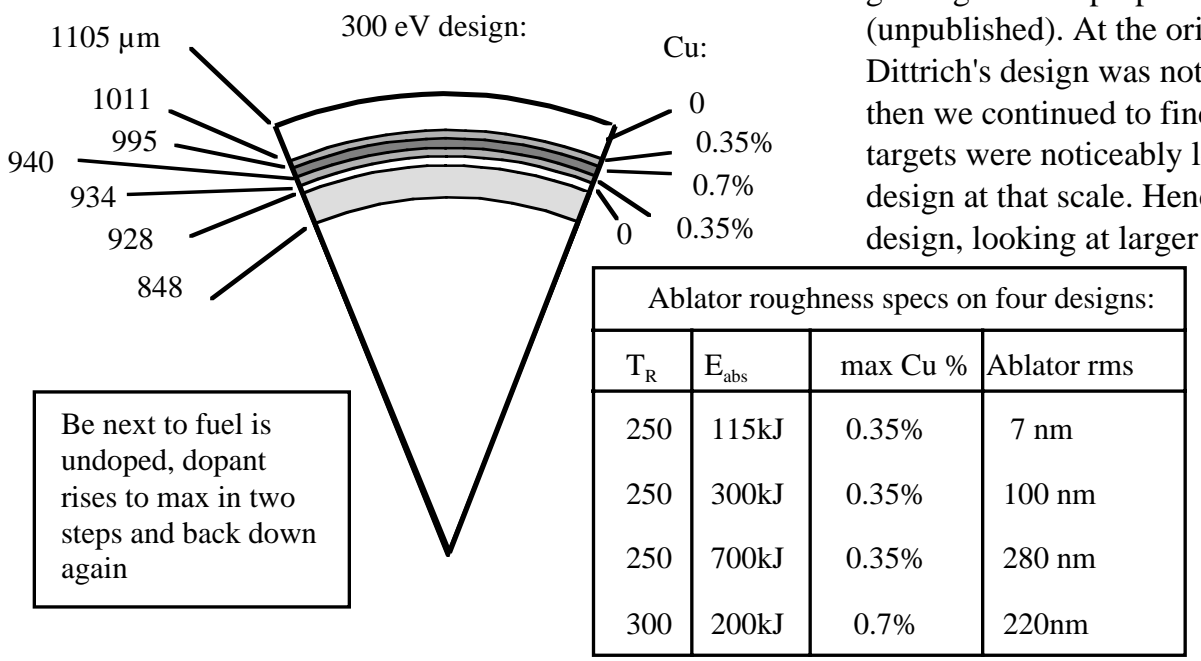

mentioned above, the roughness specifications are a strong function of power and energy, so that there is likely to be more impact on them from laser and hohlraum performance than from this reoptimization.)

This scan technique has been applied to a variety of targets, including the polyimide $1.1 \mathrm{~mm} 300 \mathrm{eV}$ capsule, $\mathrm{CH}+0.25 \% \mathrm{Ge}$ at the same outer radius and peak drive, and four ablator materials at $250 \mathrm{eV}: \mathrm{CH}, \mathrm{CH}(\mathrm{Ge})$, polyimide, and $\mathrm{Be}(\mathrm{Cu})$. We find that at $250 \mathrm{eV}$, undoped $\mathrm{CH}$ is comparable in performance to uniformly doped $\mathrm{Be}(\mathrm{Cu})$. Both are considerably superior to polyimide and doped $\mathrm{CH}$. Full specifications for these targets are still being developed.

\section{GRADED DOPED BERYLLIUM}

At the time of this meeting, in June 2003, we had just begun looking at graded doped beryllium capsules. Further work since then has been quite exciting. Because it is very relevant to target fabrication, we are including that work in this paper even though the material was not presented at the conference.

Graded dopants have been considered previously, in fact the original NIF designs used graded $\mathrm{Na}$ and $\mathrm{Br}$ dopants in $\mathrm{Be}$, as did the $250 \mathrm{eV}$ design describe in Lindl. ${ }^{3}$ These early designs were not optimized in detail, and used monotonically decreasing dopant concentration. More recently, Dittrich ${ }^{4}$ did a detailed optimization of a graded doped capsule meant to be driven at very low energy and temperature $(115 \mathrm{~kJ}$ absorbed and $250 \mathrm{eV})$. Dittrich used a grading scheme proposed by Hatchett (unpublished). At the original very small scale, Dittrich's design was not very robust, but since to find that other $250 \mathrm{eV}$ less robust than Dittrich's design at that scale. Hence we reexamined this design, looking at larger more typical NIF scales, as well as considering a similar $300 \mathrm{eV}$ design.

These designs are much less susceptible to acceleration-phase Rayleigh-Taylor growth than any other

Figure 1. Be capsule with graded $\mathrm{Cu}$ dopant. The $300 \mathrm{eV}$ design is shown. the $250 \mathrm{eV}$ designs are scales of the design by Dittrich (ref. 2). The table shows the allowed ablator rms roughness ( $1 / 3$ of the ablator perturbation that causes $50 \%$ yield degradation. 
ignition target that we have modeled. Figure 1 shows the $300 \mathrm{eV}$ design, and the RayleighTaylor results for the cases we have examined. The quantity tabulated as "ablator rms" is one third of the ablator surface roughness, with the NIF standard spectrum in spherical harmonic modes 12 and above, that causes yield degradation to $50 \%$ of clean. Typically, past capsules have required 20-40 nm. Dittrich's original design is included in the table; its specification is indicated, which for its size it is the most stable $250 \mathrm{eV}$ design known. The other scales, and the $300 \mathrm{eV}$ design, can tolerate very rough surfaces.

Even though sputtered beryllium surfaces have been considered unacceptably rough, these designs are stable enough to tolerate existing sputtered surface roughness. The technology of constructing graded layers is probably a straightforward extension of sputtered beryllium fabrication: one changes, as a function of time, the copper concentration in the growing layer. Issues remain of filling and characterizing the layer, as in all beryllium capsules, but the additional stability of these capsules probably makes them more forgiving of the possible solutions to these issues.

The $300 \mathrm{eV}$ capsule is also very tolerant of short wavelength ice perturbations. The thick ablator and high ablation velocity make for low feed-out and low growth. The simulations used the old spectrum as described in ref. 2. A $5 \mu \mathrm{m}$ rms ice roughness produces $50 \%$ yield; a specification would be $1.7 \mu \mathrm{m}$. For this spectrum with $1.7 \mu \mathrm{m}$ rms total, the rms in modes $10-15$, which are likely to be the most important, is 0.46 $\mu \mathrm{m}$. For comparison, typical recent Omega ice surfaces can be described as approximately

$$
\mathrm{R}_{\mathrm{lm}}=10 \mu \mathrm{m} l^{-1.8} \text {. }
$$

Such a spectrum has total $\mathrm{rms} 5.4 \mu \mathrm{m}$, somewhat higher than the best Omega surfaces of $1.8 \mu \mathrm{m} \mathrm{rms}$. With an $l^{-1.8}$ spectrum, with a total $\mathrm{rms}$ of $5.4 \mu \mathrm{m}$, the rms in modes $10-15$ is 0.39 $\mu \mathrm{m}$. Hence we can tentatively draw the remarkable conclusion that this capsule could tolerate "typical" Omega ice roughness, including the nominal safety factor of three. This conclusion does not extend to modes below 10 , for which (see below) we expect the specification to be similar to the typical requirement as given in ref. 1 . Hence achieving adequate low modes will be the primary challenge for the ice in this capsule. Any surface that has adequate low modes will very likely have more than adequate amplitudes for modes above 10 .

As just implied, we examined the sensitivity of the $300 \mathrm{eV}$ graded-doped capsule to low modes in the ice and ablator. Its sensitivity is very similar to the baseline polyimide capsule - the growth factors for low modes, and the amount of bang-time low mode perturbation that the capsule can tolerate, are virtually identical to the baseline. The extraordinary features of this capsule are only in the growth of perturbations with mode numbers greater than about 15 .

Fielding scenarios for these capsules include the possibilities of fill tubes and fill holes. Their remarkable high-mode stability, together with the high-mode structure that is characteristic of fill tubes and holes, suggest that these capsules may be able to tolerate relatively large fill tubes and holes. While we have not had the opportunity to do full simulations, we can use growth factors inferred from less difficult simulations to estimate how large a tube or hole might be tolerated. These estimates are based on linear analysis, and a fill feature is certainly not linear. The only reason to hope that the analysis might be approximately correct is if the very short wavelength characteristics do not matter, and the evolution is dominated by the average mass defect as it seeds the fastest-growing modes, which are much larger than the lateral size of the feature. For other targets for which we have done detailed fill hole simulations, linear analysis estimates give reasonable results: for baseline polyimide, linear analysis indicates that a fill hole should be less than 2-4 $\mu$ m diameter, and a fill tube diameter, divided by the tube's $\rho^{0.333}$ to give equivalent mass defect, should be less than 8-12 $\mu \mathrm{m}$. Using growth factors for the $300 \mathrm{eV}$ graded doped capsule, we find that a hole should be less than 10-15 $\mu \mathrm{m}$ diameter, and a tube less than 15-20 $\mu \mathrm{m}$ diameter. (There is less leverage of the growth factors on the tube than on the hole: the effective mass defect for the tube goes as the cube of the tube size, since this approximation assumes that a few tube diameters contribute to the mass defect, while the mass defect for the hole goes as the square of the hole diameter.) Of course these numbers are very preliminary, but they provide a rough idea of how important the increased stability might be to fill tube and hole requirements.

Because these capsules are so robust with respect to short wavelengths, there may be a 
better optimization with somewhat thinner shells producing a higher velocity implosion that is more tolerant of low mode irregularities while still having satisfactory behavior with respect to high modes. That is an obvious area of future work, as well as simulations of holes and tubes.

\section{FILL HOLES AND TUBES, AND ISOLATED DEFECTS}

Detailed simulations of fill tubes and holes, and of the tent supporting the capsule, are an important area of work for all targets. At the time of this writing there is not anything substantially new to report. The new graded beryllium capsules will be especially interesting to simulate. Specifications as they stand now for baseline capsules are:

Fill hole $<5 \mu \mathrm{m}$ diameter

Fill tube $<10 \mu \mathrm{m} / \rho^{0.33}$ diameter, $\rho$ in $\mathrm{g} / \mathrm{cc}$

Tent $<0.1 \mu \mathrm{m}$ thick

Any other localized perturbations smaller than about $20 \mu \mathrm{m}$ in lateral dimensions should have mass defect less than what corresponds to the above, which is $3 \mathrm{x}$ larger than the isolated defect requirement described in Ref. 1 for small defects. For large defects - larger than $20 \mu \mathrm{m}$ laterally — the analysis described in Ref. 1 has a conceptual flaw ${ }^{5}$ and has been reconsidered. The analysis presented there assumed Gaussian perturbations. For defects $20 \mu \mathrm{m}$ or smaller, the Gaussian assumption is acceptable, since the amplitude of the fast-growing modes is determined by the mass present in the perturbation. For larger defects, perturbation can contain higher modes and can couple better to the fast growing modes than a Gaussian. We have calculated the growth of various perturbation shapes and find that perturbations larger laterally than $20 \mu \mathrm{m}$ should be smaller than the surface roughness requirement (typically $30 \mathrm{~nm}$ ) if they are troughs or ridges. If they have similar extent in both lateral directions ("bumps, pimples, or divots"), they can be about 50 times bigger than the rms surface roughness requirement (typically, then, about 1 micron). These numbers are for a typical baseline polyimide target; a new target reoptimized in the manner of Herrmann would be able to tolerate perturbations about twice these numbers, and the $300 \mathrm{eV}$ graded doped Be target described above would be able to tolerate defects about 10 times this big.

\section{SYSTEMATIC ALLOCATION OF ERROR BUDGET}

Another important area of current work is an effort to systematically evaluate all of the specifications and their relative impact. We know the ideal implosion that we are attempting to approach: spherically symmetric and perfectly timed. Every source of error or imperfection moves us away from this ideal. Over the last 15 years, specifications have been written for the laser, the fielding system, target fabrication, cryogenics, and for the programs that will provide pulse-shaping and symmetry. Concurrently, our modeling capability, and our understanding of the overall system, have continued to improve. Now we intend to review each top level specification and its relative impact, in order to produce an "error budget" from which it is readily evident how we can best tradeoff the various sources of imperfection. While it is still too early in this work to present any quantitative result, there are two qualitative conclusions that have become evident. The first is that the largest single source of imperfection is very likely to be the intrinsic radiation asymmetry (that is, the asymmetry that would be present even if the laser power balance and pointing, and target fabrication, were all perfect). Our current estimate is that the intrinsic asymmetry uses up 20-35\% of the total error budget, while the second largest sources of error use about $10 \%$. Hence it is clearly very important to keep the intrinsic asymmetry under control. The second qualitative conclusion is the large number of small sources of imperfection. The draft error budget as it now exists contains 22 entries. Hence, on average, each can only use less than $4 \%$ of the total error budget. While each of these has been specified so that the total leaves adequate margin, the sheer number of issues that contribute emphasizes the importance of quantifying each one and its relative impact. It is also clearly important that we properly evaluate the overall impact of the wide variety of sources of imperfection.

\section{3D SIMULATIONS}

Our program of 3D simulations with the code $\mathrm{HYDRA}^{6}$ continues. Hydra now has all of the physics necessary to do 3D non-LTE integrated simulations, as well as the capsule implosions we have been doing for a few years. 
The 3D simulations of the NIF hohlraum suggested a number of design improvements. The pattern of energy flow in the LEH is three dimensional, and the LEH blows up somewhat more in $3 \mathrm{D}$ because of the proximity of high intensity beams to the lip at some locations. This necessitates increasing the thickness of the $\mathrm{CH}$ liner on the LEH from 20 to $30 \mu \mathrm{m}$. (The original nominal value was in fact $30 \mu \mathrm{m}$, but a tightening of the optimization in 2D had led to a reduction to $20 \mu \mathrm{m}$.)

A full redesign of the hohlraum and pointing was done with a cocktail-wall hohlraum $10.5 \mathrm{~mm}$ long. The capsule was a polyimide ablator, radii 946,1034 , and $1193.5 \mu \mathrm{m}$. It is driven with $1.49 \mathrm{MJ}$ of $0.3 \mu \mathrm{m}$ light, peak power $390 \mathrm{TW}$, in an $18.5 \mathrm{~ns}$ pulse.

The result of these improvements in the hohlraum design, and then reoptimizing the cone-to-cone beam balance, was a hohlraum design with very good symmetry. (Although, as described above, the remaining asymmetry is the largest single source of imperfection in the modeled implosion.) Having achieved this asymmetry, we imposed it on a series of capsuleonly implosions.

A simulation that has the $3 \mathrm{D}$ hohlraum asymmetry, and nominal capsule imperfections, gives $21 \mathrm{MJ}$ of yield. This included a "NIF standard" spectrum of perturbations on the ablator, including the low modes for which the NIF standard is very similar to the published specification. ${ }^{1}$ Low mode ice perturbations were set to the published specification, ${ }^{1}$ and high modes were given a power-law shape typical of recent Omega cryo target characterization (as described above) with the amplitudes scaled so that the rms was $1.7 \mu \mathrm{m}$ which they have seen on their best surfaces. Intermediate modes smoothly interpolated between the low-mode specifications and the high-mode standards as described above.

The good performance of this implosion gives us confidence that the various sources of perturbation, in combination, act as we expect from 2D simulations and past spot-checks with the $3 \mathrm{D}$ code.

\section{SUMMARY}

This article has described several advances in our modeling and understanding. Systematic scans of the parameter space of possible capsules has resulted in significant improvements in simulated performance, providing more margin for looser specifications or for errors in our understanding. We found that radially grading the dopant concentration in $\mathrm{Be}(\mathrm{Cu})$ capsules produces a remarkable increase in the shortwavelength stability. And finally, simulations in 3D have indicated hohlraum design improvements, and demonstrated good performance in simulations that include all nominal sources of deviation. Overall, these results continue to increase our confidence in achieving ignition with indirect drive on NIF.

\section{ACKNOWLEDGEMENT}

This work was performed under the auspices of the U.S. Department of Energy by the University of California, Lawrence Livermore National Laboratory under contract No. W-7405-Eng-48.

\section{REFERENCES}

${ }^{1}$ S.W. Haan, T. Dittrich, G. Strobel, S. Hatchett, D. Hinkel, M. Marinak, D. Munro, O. Jones, S. Pollaine, and L. Suter, "Update on ignition target fabrication specifications," Fusion Science and Tech. 41, 165 (2002).

${ }^{2}$ R.B. Stephens, S.W. Haan, and D.C. Wilson, "Characterization specifications for baseline indirect drive NIF targets," Fusion Science and Tech. 41, 226 (2002).

${ }^{3}$ J. Lindl, Inertial Confinement Fusion, SpringerVerlag, New York (1998), p. 162

${ }^{4}$ T.R. Dittrich, S.W. Haan, M.M. Marinak, S.M. Pollaine, and R. McEachern, "Reduced scale National Ignition Facility capsule design," Phys. Plasmas 5, 3708 (1998).

${ }^{5}$ Bob Cook, private communication (2002).

${ }^{6}$ M. M. Marinak, G.D. Kerbel, N.A. Gentile, O. Jones, D. Munro, S. Pollaine, T.R. Dittrich, and S.W. Haan, "Three-dimensional HYDRA simulations of National Ignition Facility targets," Phys. Plasmas 8 (5), 2275 (2001). 